\title{
RANCANG BANGUN SISTEM INFORMASI GEOGRAFIS UNTUK MEMBANTU PENCARIAN JALUR TERPENDEK MENUJU ATM BANK BRI DENGAN METODE TABU SEARCH ALGORITHM (TS)
}

\author{
Ummulhadi'), Harlinda L.2) \\ ummulhadi09@gmail.com ${ }^{1)}$,hj.linda@yahoo.com ${ }^{2)}$ \\ 1,2) Prodi Teknik Informatika, Universitas Muslim Indonesia-Makassar
}

\begin{abstract}
Abstrak
Salah satu permasalahan utama bagi nasabah suatu Bank adalah jalur yang harus mereka tempuh. Hal ini disebabkan oleh banyaknya jumlah ATM dan jalur alternatif yang ada. Sehingga, tidak sedikit waktu dan biaya yang dibutuhkan untuk mencari mesin ATM yang ada serta jalur yang harus ditempuh. Untuk itu dibutuhkan sebuah alternatif yang dapat mempermudahd alam pencarian rute tercepat menuju ATM Bank BRI. Metode yang digunakan untuk menentukan jalur terpendek dalam penelitian ini adalah metode Tabu Search Algorithm, dengan mencari cost terendah dari beberapa iterasi yang ada. Dengan menginputkan titik awal berupa nama jalan yang nantinya diproses dalam sistem yang menghasilkan output berupa data jalur yang ditampilkan dalam map. Dengan mengambil sebuah contoh pencarian ATM untuk lokasi Maccini Sawah 1 ditemukan sebuah jalur terpendek dengan cost 2100 serta alternative jalur menunjukkan cost 2800 dengan selisih 700 cost yang berarti jalur tersebut merupakan jalur yang terdekat.
\end{abstract}

Kata kunci: Nasabah Bank, ATM, Jalur terpendek, Tabu Search Algorithm.

ILKOM Jurnal Ilmiah work is licensed under a CCA-SA 4.0 International License.

\section{Pendahuluan}

Pada periode ini terjadi peningkatan dan perkembangan yang sangat pesat dari alat pembayaran non tunai dengan media kartu, seperti kartu debet, kartu kredit dan kartu ATM [1]. Hal ini lebih disebabkan meningkatnya jumlah pemegang kartu dan transaksinya yang diikuti pula dengan meningkatnya nilai transaksi.

Peningkatan aktivitas ATM antara lain disebabkan oleh makin luasnya jaringan pelayanan ATM, baik akibat penambahan mesin maupun sebagai akibat dari makin banyaknya bank yang menjadi anggota switching ATM. Sedangkan alat pembayaran non tunai dengan media kertas masih terdiri dari cek, bilyet giro, wesel bank, not debet, nota kredit dan beberapa warkat kliring lainnya. Bank BRI adalah salah satu bank yang memiliki fasilitas mesin ATM yang banyak tesebar di penjuru nusantara mulai dari pelosok hingga ke kota -kota besar salah satunya di kota Makassar [1].

Penyebaran ATM Bank BRI kota Makassar saat ini sangat berkembang pesat, dimana hampir setiap kecamatan maupun kelurahan yang ada di kota Makassar terdapat mesin ATM diantaranya kecematan Biringkanaya, Tallo, Rappocini, Tamalate, Tamalanrea, Panakukang, Manggala, Ujung Pandang, Wajo, Mamajang, dapat ditemukan beberapa mesin ATM yang ditempatkan di lokasi strategis seperti kampus, kantor pemerintahan, pertamina, mall, hotel dan tempat-tempat perbelanjaan diantaranya Alfamart, Alfamidi, dan Indomaret. Karena banyaknya tempat-tempat penyebaran mesin ATM ini terkadang seorang nasabah sulit untuk menentukan ATM mana yang terdekat dari lokasi ia berada saat ini.

Proses pencarian jalur terpendek ke lokasi ATM membutuhkan banyak tenaga, biaya dan waktu maka dibutuhkan sebuah sistem yang mencakup semua informasi tentang lokasi penyebaran serta informasi jalur terpendek menuju ATM di kota Makassar. Salah satu alternatif untuk mengetahui lokasi penyebaran ATM di kota Makassar yaitu dengan adanya sebuah sistem informasi geografis berbasis website yang memanfaatkan metode Tabu Search Algorithm (TS).

Tujuan utama suatu Tabu Search Algorithm (TS), adalah mencegah suatu proses pencarian dari penyimpanan pencarian, agar tidak terjadi pencarian ulang pada penyimpanan solusi yang sudah pernah ditelusuri, dengan memanfaatkan suatu struktur memori yang mencatat jejak proses pencarian yang sudah dilakukan dalam proses Tabu Search Algorithm (TS)[2]. Algoritma ini menggunakan tabu list untuk menyimpan sekumpulan solusi yang baru saja dievaluasi, hasilnya akan disesuaikan terlebih dahulu dengan isi pada tabu list untuk melihat apakah solusi tersebut sudah ada atau tidak. 


\section{Landasan Teori \\ 2.1 ATM}

Pengertian ATM (Automatic Teller Machine) menurut Allen H. Lipis adalah Alat kasir otomatis tanpa orang, ditempatkan di dalam atau di luar pekarangan bank, yang sanggup untuk mengeluarkan uang tunai dan menangani transaksi-transaksi perbankan yang rutin. ATM (Automatic Teller Machine)di Indonesia juga dikenal dengan Anjungan Tunai Mandiri. (Astuti, 2011) [1].

ATM (Anjungan Tunai Mandiri / Automatic Teller Machine) merupakan salah satu teknologi yang menerapkan konsep proses data berbasis Digital. Device ini mempunyai dua bagian penting yaitu Hardware yang terdiri dari Unit Pemroses dalam hal ini PC, serta sistem device interface yang menghubungkan pemakai/User melalui suatu kartu magnetik, dan Software yang berfungsi sebagai interface yang menghubungkan User dengan Sistem dalam kaitan Data (Informasi).

Kartu ATM adalah kartu yang dapat digunakan untuk penarikan tunai baik di countercounter bank maupun pada ajungan ATM. Dalam kartu ATM ini terdapat Magnetic strip yang merupakan suatu bentuk plastik pendek yang dilapisi dengan sistem magnit dan biasanya dilekatkan pada kartu kredit ataupun kartu berharga lainnya. Pada magnetic strips biasanya tertulis data pribadi pemegang kartu, yang berisi nomor rekening, nomor pribadi serta kode aksesnya. Dan tulisan ini ditulis dalam bentuk kode-kode tertentu, dan hanya bisa dibaca oleh komputer yang dilengkapi dengan mesin khusus untuk kartu magnetic strip tersebut.

\subsection{Rancang Bangun}

Rancang merupakan serangkaian prosedur untuk menerjemahkan hasil analisa dari sebuah sistem ke dalam bahasa pemrograman untuk mendeskripsikan dengan detail bagaimana komponen-komponen sistem diimplementasikan[9]. Rancangan sistem adalah penentuan proses dan data yang diperlukan oleh sistem baru [9]. Perancangan adalah kegiatan yang memiliki tujuan untuk mendesain sistem baru yang dapat menyelesaikan masalah-masalah yang dihadapi perusahaan yang diperoleh dari pemilihan alternatif sistem yang terbaik [9]. Sedangkan pengertian bangun atau pembangunan sistem adalah kegiatan menciptakan sistem baru maupun mengganti atau memperbaiki sistem yang telah ada baik secara keseluruhan maupun sebagian [9]. Bangun sistem adalah membangun sistem informasi dan komponen yang didasarkan pada spesifikasi desain [10].

Dengan demikian pengertian rancang bangun merupakan kegiatan menerjemahkan hasil analisa dalam bentuk paket perangkat lunak kemudian menciptakan sistem tersebut ataupun memperbaiki sistem yang sudah ada.

\subsection{Sistem Informasi Geografis}

Sistem Informasi Geografi (SIG) atau yang juga dikenal dengan Sistem Informasi keruangan adalah sistem informasi berbasis komputer yang digunakan untuk mengumpulkan, menyimpan, menggabungkan, mengatur, mentransformasi, memanipulasi dan menganalisis data yang bergeoreferensi[3].

Sistem Informasi Geografi (SIG) akan menghasilkan informasi yang lebih berkualitas dan informasi yang disajikan tersebut dapat dengan mudah dipahami oleh pengguna, sesuai dengan perkembangan ilmu pengetahuan dan teknologi terkini pembuatan peta pun bisa dilakukan tidak dengan cara konvensional (sederhana), melainkan sudah dikembangkan dengan menggunakan komputer sehingga menjadi lebih mudah dan cepat [3]

Dilihat dari definisinya, Sistem Informasi Geografi (SIG) merupakan suatu sistem informasi yang didesain untuk bekerja dengan data yang direferensikan oleh spasial atau koordinat geografi yang terkomputerisasi. Dengan kata lain, Sistem Informasi Geografi (SIG) adalah sistem informasi berbasis komputer yang digunakan untuk mengolah dan menyimpan data atau informasi geografis [3].

\subsection{Tabu Search Algorithm}

Tabu Search Algorithm (TS) merupakan salah satu algoritma yang berada dalam ruang lingkup metode heuristik. Algoritma ini menggunakan short-term memory untuk menjaga agar proses pencarian tidak terjebak pada nilai optimum lokal. Algoritma ini menggunakan tabu list untuk menyimpan sekumpulan solusi yang baru saja dievaluasi. Selama proses optimasi pada setiap iterasi, solusi yang akan dievaluasi akan dicocokkan terlebih dahulu dengan isi tabu list untuk melihat apakah solusi tersebut sudah ada pada tabu list[2]. 
Apabila solusi tersebut sudah ada pada tabu list, maka solusi tersebut tidak akan dievaluasi lagi pada iterasi berikutnya. Dan jika sudah tidak ada lagi solusi yang tidak akan menjadi anggota tabu list, maka nilai terbaik yang baru saja diperoleh merupakan solusi yang sebenarnya [2].

\section{Metode}

Metode yang digunakan dalam pengumpulan data sebagai dasar penelitian adalah keterangan sebagai bahan kelengkapan data dan informasi meliputi:

\subsection{Observasi}

Teknik Observasi yaitu teknik pengumpulan data dengan mengamati secara langsung objek penelitian, kemudian mencatat permasalahan.

\subsection{Dokumenter}

Teknik Dokumentera dalah teknik pengumpulan data dengan mengumpulkan data yang relevan dengan masalah yang diteliti. Secara teknis, penulis mengumpulkan data yang diperoleh melalui Bank BRI.

\section{Hasil}

Proses pencarian jalur terpendek dilakukan dengan cara meginputkan titik awal berupa nama jalan kemudian menampilkan sebuah gambar berupa peta. Contoh kasus yang diimplementasikan yaitu pencarian jalur terdekat ATM BRI di lokasi Maccini Sawah. Jalur hasil yang ditampilkan adalah seperti pada Gambar 1.

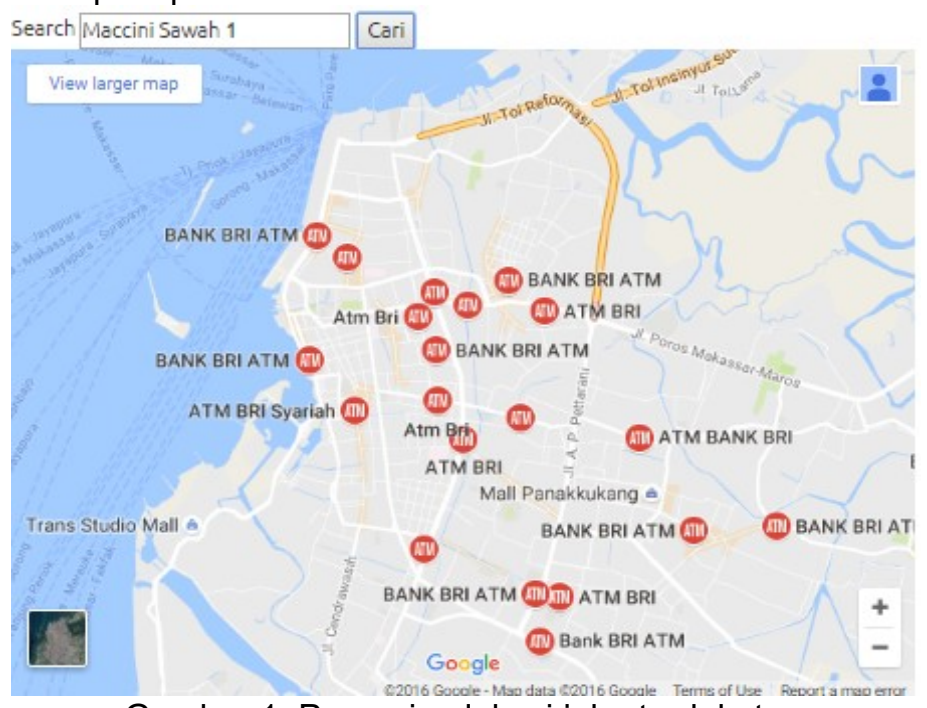

Gambar 1. Pencarian lokasi jalur terdekat

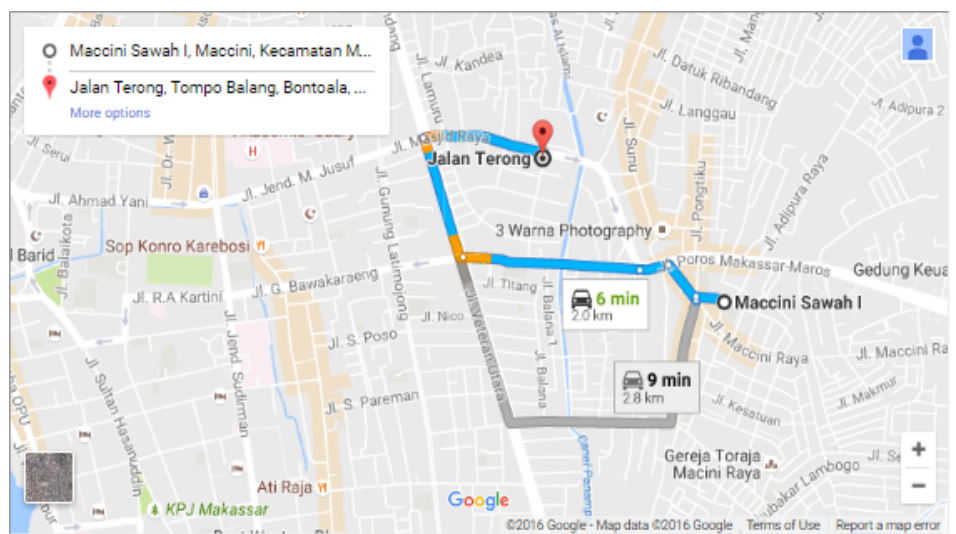

Gambar 2. Map Jalur terdekat ATM BRI Maccini Sawah 1

Dari gambar 2 terbentuk sebuah graf yang merupakan pencarian jalur dari Jalan Maccini Sawah 1 ke Jalan. Terong. 


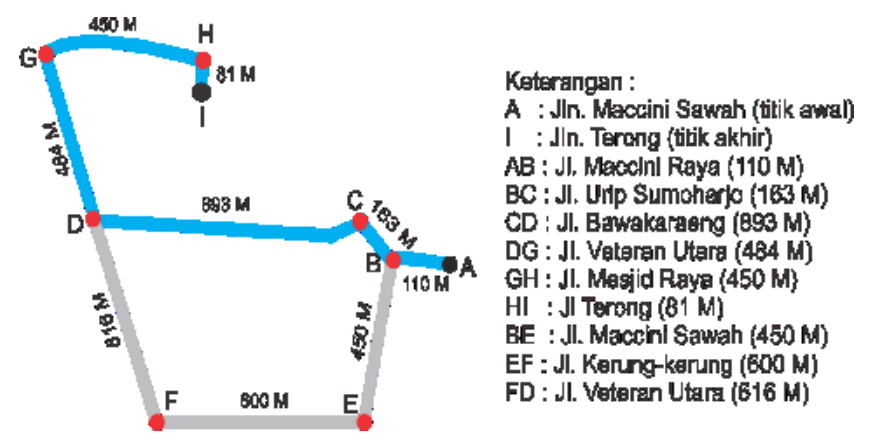

Gambar 3. Graf Jalur Maccini Sawah 1 menuju Terong

Proses iterasi graf $\mathrm{A}$ ke $\mathrm{J}$ adalah sebagai berikut :

\section{Iterasi 1-0 : CariJalurdari A ke I}

a. Iterasi I-0

Posisi di node $A$ Node tetangganya $B$ jarak $A B=110$ meter. Maka bergerak ke B. Tabu queue sekarang $=[A B]$ Jalur saat ini : $A-B$

b. Iterasi l-1

Posisi di node $B$ Node tetangganya $A, C$ dan E.jarak $B A=110$ meter, $B C=163$ meter, $\mathrm{BE}=450$ meter. A sudah pernah dilewati. Hapus AB. Tabu queue masih kosong. Sehingga $B C$ dan BE layak untuk dijalani. BE

Tidak. Hanya BE yang tersisa. Maka bergerak ke E.Tabu queue sekarang = $[\mathrm{AB}, \mathrm{BE}]$ Jalur saat ini : A-B-E Dan seterusnya hingga Iterasi I-3, ditemukan jalur A-B-C-D-H-I, total jarak 2.100 meter. Tabu queue sekarang $[A B, B C, C D, D H, H I]$ Jalur terbaik adalah A-B-C-D-G-H-I.

\section{Iterasi I-1 : Cari Jalur Alternatif dari A ke J}

a. Iterasi I-0

Posisi di node $A$ Node tetangganya $B$ jarak $A B=110$ meter. Graf $A B$ ada dalam Tabu queue. Hapus AB.Tabu queue sekarang $=[A B, B C, C D, D H, H I$, ] Jalur saat ini : A-B

b. Iterasi I-1 Posisi di node $B$

Node tetangganya A, C, E. Jarak BA $=110$ meter, $B C=163$ meter, $B E=450$ meter. AB sudah pernah dilewati. Hapus BA. BC ada dalam Tabu queue. Hapus BC. Tersisa $B E$. BE memiliki jarak rendah. Maka bergerak ke BE. Tabu queue sekarang $=[A B$, $B C, C D, D G, G H, H I, B E]$. Jalur saat ini : A-B-E

Dan seterusnya hingga Iterasi J-2, ditemukan jalur A-B-E-F-G-H, total jarak 2800 meter. Tabu queue sekarang $[\mathrm{AB}, \mathrm{BC}, \mathrm{CD}, \mathrm{DG}, \mathrm{GH}, \mathrm{HI}, \mathrm{BE}, \mathrm{EF}, \mathrm{FD}]$.

Setelah melakukan iterasi, ditemukan alternatif jalur sebagai berikut:

0 . A-B-C-D-G-H-I, jarak 2100 meter.

1. A-B-E-F-G-H-I, jarak 2800 meter

Dalam kasus contoh ini, karena edge dan node yang dilalui sangat terbatas jumlahnya. Terdapat jarak terbaik yaitu 2100 meter, angka 2100 meter sudah menjadi jarak terbaik. Sehingga iterasi dihentikan. Maka jalur terbaik yang dipakai adalah A-B-C-D-G-H-I, dengan jarak 2100 meter.

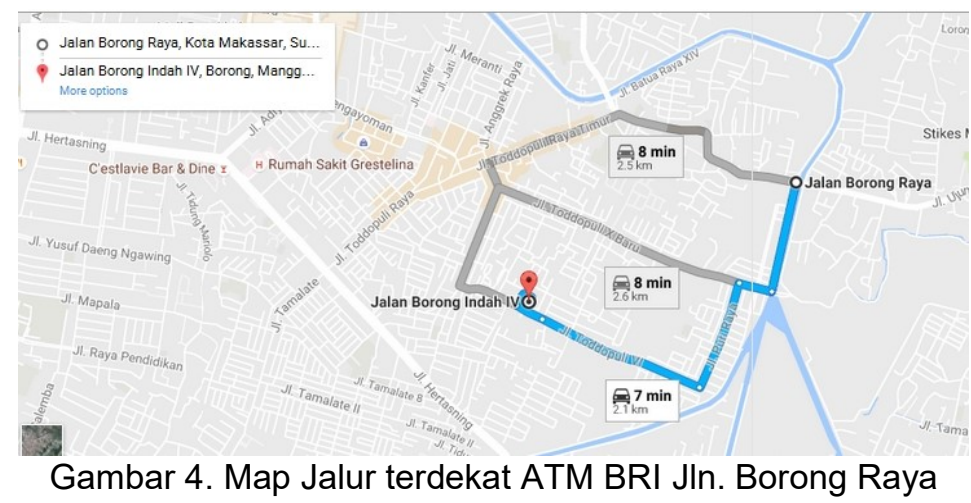

Dari gambar 4. terbentuk sebuah graf yang merupakan pencarian jalur dari Jalan Borong Raya ke Jalan Borong Indah IV. 


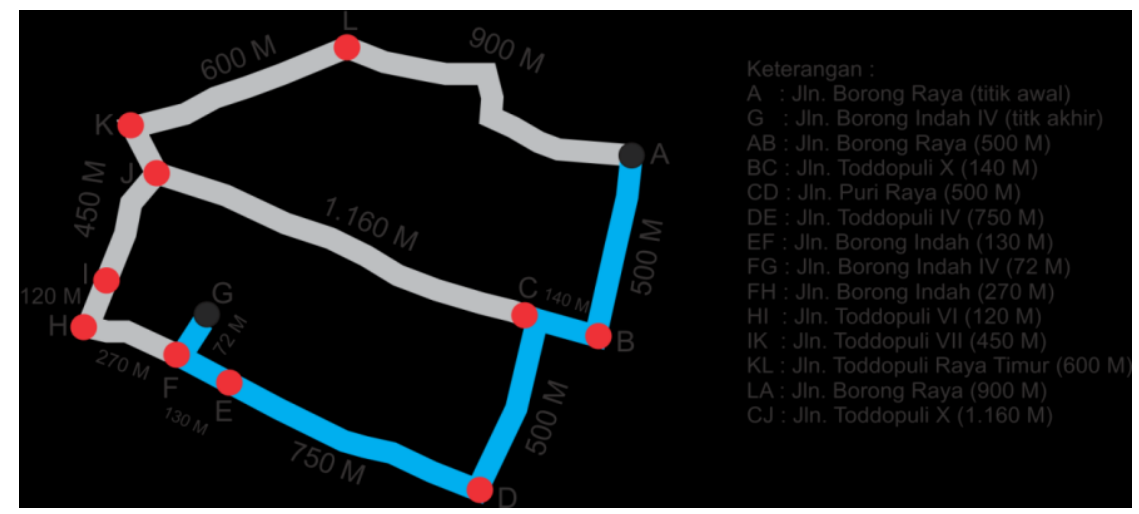

Gambar 5. Graf Jalur Borong Raya menuju Borong Indah IV

Proses iterasi graf $A$ ke $G$ adalah sebagai berikut :

1. Iterasi 1-0 : Cari Jalur dari A ke G

a. Iterasi I-0

Posisi di node $A$ Node tetangganya $B$ dan $L$, jarak $A B=500$ meter, jarak $A L=900$ meter. Tabu queue masih kosong. Sehingga $A B$ dan $A L$ layak untuk dijalani. Jarak $A B$ yang paling kecil. Maka bergerak ke $B$. Tabu queue sekarang $=[A B]$ Jalur saat ini : $A-$ $\mathrm{B}$

b. Iterasi l-1

Posisi di node $B$ Node tetangganya $A$, dan $C$. jarak $B A=500$ meter, dan $B C=140$ meter. Node A sudah pernah dilewati. Hapus AB. Tabu queue masih kosong. Sehingga BC layak untuk dijalani.

Hanya ada BC yang tersisa. Maka bergerak ke C. Tabu queue sekarang = $[A B, B C]$ Jalur saat ini : A-B-C Dan seterusnya hingga Iterasi I-4, ditemukan jalur A-B-C-D-EF,G total jarak 2.100 meter. Tabu queue sekarang $[A B, B C, C D, E F, F G]$ Jalur terbaik adalah A-B-C-D-E-F-G.

2. Iterasi I-1 : Cari Jalur Alternatif dari A ke G

\section{a. Iterasi I-0}

Posisi di node $A$ Node tetangganya $B$ dan $L$, jarak $A B=500$ meter, jarak $A L=900$ meter. Tabu queue masih kosong. Node $A B$ sudah pernah dilewati. Hapus $A B$. Hanya ada $A L$ yang tersisah. Maka Bergerak ke $A L$. Tabu queue sekarang $=[A B, B C, C D$, $E F, F G, A L]$ Jalur saat ini : $A-L$

b. Iterasi I-1

Posisi di node $L$. Node tetangganya $A, K$. Jarak $A L=900$ meter, dan $L K=600$ meter. $\mathrm{AL}$ sudah pernah dilewati. Hapus AL. Tabu queue masih kosong. Sehingga LK layak untuk dijalani.

Hanya $A L$ yang tersisa. Maka bergerak ke $L$. Tabu queue sekarang $=[A B, B C, A L]$ Jalur saat ini : A-B-L Dan seterusnya hingga Iterasi I-4, ditemukan jalur A-B-L-K-I-H-FG total jarak 2.500 meter. Tabu queue sekarang $[A B, B C, C D, E F, F G, L K, ~ K I, I H, H F$ ] maka jalur terbaik saat ini adalah A-B-L-K-I-H-F-G.

3. Iterasi I-1 : Cari Jalur Alternatif dari A ke G

a. Iterasi I-0

Posisi di node $A$ Node tetangganya $B$ dan $L$, jarak $A B=500$ meter, jarak $A L=900$ meter. Tabu queue masih kosong. Node $A B$ dan $A L$ sudah pernah dilewati. Node $A B$ yang paling kecil. Maka Bergerak ke $A B$. Tabu queue sekarang $=[A B, B C, C D, E F$, $\mathrm{FG}, \mathrm{AL}]$ Jalur saat ini : A-B

b. Iterasi l-1

Posisi di node $B$. Node tetangganya A, C. Jarak AC= 140 meter, dan $C J=1160$ meter. CB sudah pernah dilewati. Hapus CB. Tabu queue masih kosong. Sehingga CJ layak untuk dijalani.

Hanya CJ yang tersisa. Maka bergerak ke J. Tabu queue sekarang $=[\mathrm{AB}, \mathrm{BC}, \mathrm{CJ}]$ Jalur saat ini : A-B-C-J Dan seterusnya hingga Iterasi I-4, ditemukan jalur A-B-C-J-I$\mathrm{H}-\mathrm{F}-\mathrm{G}$ total jarak 2.600 meter. Tabu queue sekarang $[\mathrm{AB}, \mathrm{BC}, \mathrm{CD}, \mathrm{EF}, \mathrm{FG}, \mathrm{LK}, \mathrm{KI}, \mathrm{IH}$, $\mathrm{HF}, \mathrm{CJ}, \mathrm{JI}, \mathrm{IH}, \mathrm{FG}]$ maka jalur terbaik saat ini adalah A-B-L-K-I-H-F-G.

Setelah melakukan iterasi, ditemukan alternatif jalur sebagai berikut:

0. A-B-C-D-E-F-G, jarak 2.100 meter.

1. A-L-K-I-H-F-G, jarak 2.500 meter

2. A-B-C-J-I-H-F-G jarak 2.600 meter 
Dalam kasus contoh ini, karena edge dan node yang dilalui sangat terbatas jumlahnya. Terdapat jarak terbaik yaitu 2100 meter, angka 2100 meter sudah menjadi jarak terbaik. Sehingga iterasi dihentikan. Maka jalur terbaik yang dipakai adalah A-B-C-D-G-H-I, dengan jarak 2100 meter.

Di bawah ini akan diperlihatkan beberapa tampilan implementasi dari aplikasi sistem pencarian jalur terdekat menggunakan metode Tabu Search Algorithm.

Halaman form data ATM adalah halaman yang hanya dapat diakses oleh admin. Halaman ini bertujuan untuk menampilkan serta melakukan manipulasi (edit dan delete) data ATM berupa alamat, tempat, latitude dan longitude.

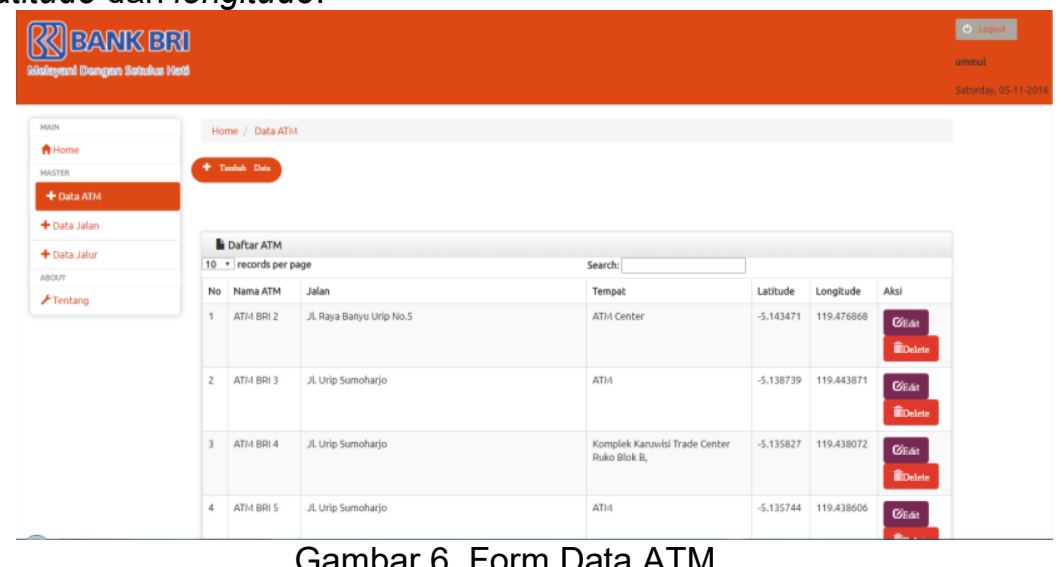

Halaman form data Jalan adalah halaman yang hanya dapat diakses oleh admin. Halaman ini bertujuan untuk menampilkan serta melakukan manipulasi (edit dan delete) data jalan berupa nama, latitude dan longitude.

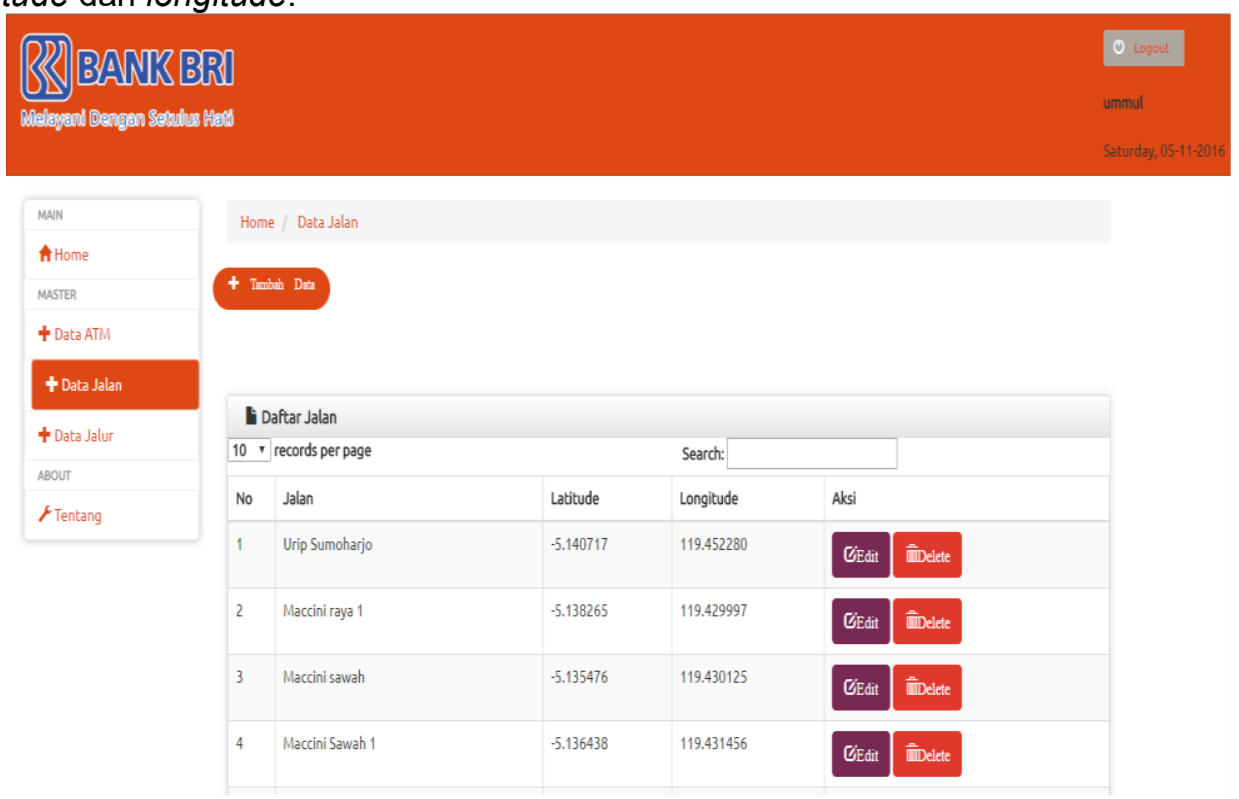

Gambar 7. Form Data Jalan

Halaman form data Jalur adalah halaman yang hanya dapat diakses oleh admin. Halaman ini bertujuan untuk menampilkan serta melakukan manipulasi (edit dan delete) data jalur berupa jalur awal, jalur akhir, data jalur, jarak.

Halaman form Pencarian adalah halaman yang ditujukan untuk user. Halaman ini menampilkan data penyebaran ATM serta dalam halaman ini dilakukan sebuah pencarian dengan mengimputkan titik awal berupa jalan. 


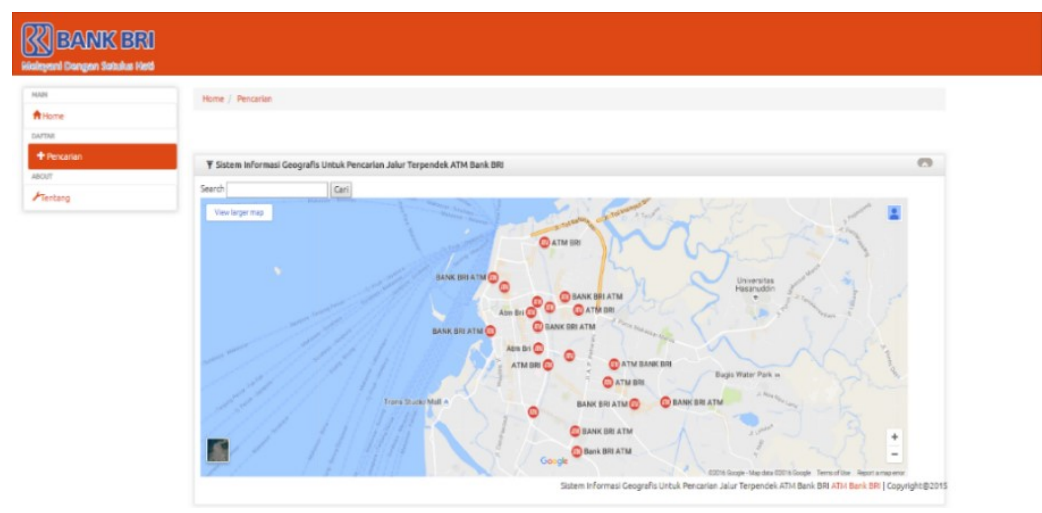

Gambar 8. Form Pencarian

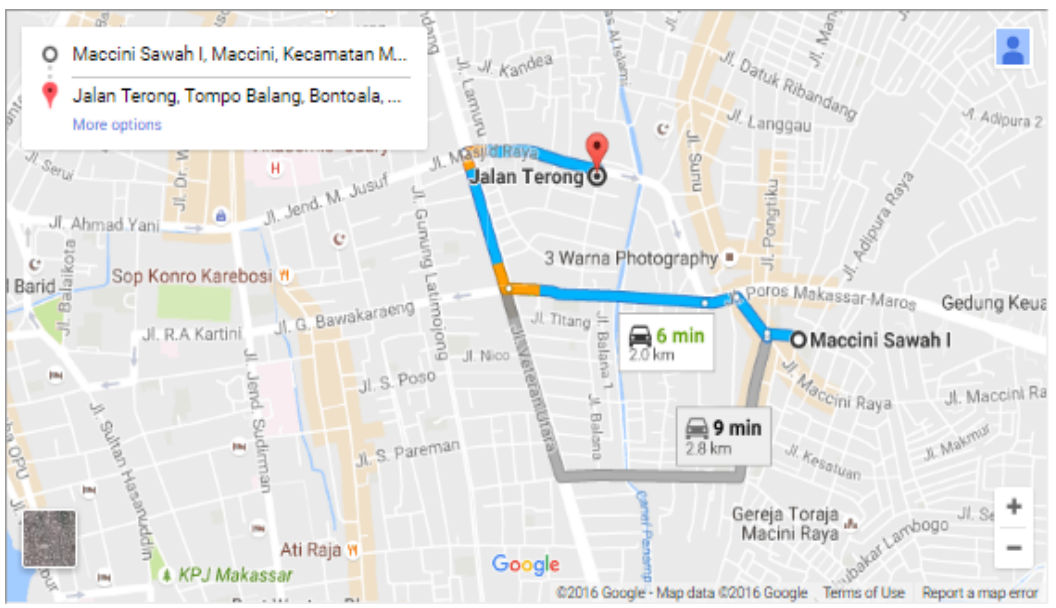

Gambar 9. Form Hasil Pencarian

\section{Kesimpulan dan Saran}

\subsection{Kesimpulan}

Setelah melakukan pengujian kepada nasabah dengan menentukan titik awal di Maccini Sawah 1 dan jalan Borong Raya ditemukan bahwa dengan menggunakan perhitungan manual Tabu Search Algorithm terbukti bahwa jalur yang ditunjukkan adalah jalur yang terdekat sesuai dengan iterasi.

\subsection{Saran}

Adapun saran-saran yang akan penulis usulkan untuk meningkatkan kinerja pencarian jalur terpendek adalah sebagai berikut:

1. Untuk memperlihatkan dan membuktikan keefektifan, kelebihan, keakuratan dan kelemahan dari Tabu Search Algorithm, maka perlu diadakan sebuah penelitian lebih lanjut dengan tujuan untuk membandingkan seluruh algoritma pencarian jalur terpendek yang ada pada berbagai data dengan jumlah titik yang lebih banyak dari yang saat ini diteliti.

2. Diharapkan agar kinerja proses pencarian jalur terpendek dari algoritma tersebut dapat lebih ditingkatkan lagi dalam hal kecepatan eksekusi pencarian dan dalam penghematan penggunaan memori computer saat melakukan proses iterasi.

3. Diharapkan bagi para pembaca agar mencoba algoritma lain agar mengetahui algoritma mana yang lebih baik dalam pencarian jalur terpendek.

\section{Daftar Pustaka}

[1] Astuti, Aris Wati. 2011. Proses Kerja Dan Dampak Dari Mesin ATM. Program Studi Akuntansi, Fakultas Ekonomi, Unikom. Bandung. Majalah IImiah UNIKOM: Vol.8, No. 1. Bandung.

[2] Togatorop, Disbun. 2014. Perancangan Aplikasi Pencarian Jalur Terpendek dengan Algoritma Tabu Search. Mahasiswa Jurusan Teknik Informatika STMIK Budi Darma, Medan, Pelita Informatika Budi Darma, Volume: VII, Nomor: 1 Juli 2014, ISSN: 2301-9425.

[3] Hermawan, I. 2009. GEOGRAFI Sebuah Pengantar, Private Publishing. Bandung. 
[4] Ivana Varita, dkk. 2013. Pencarian Jalur Tercepat Rute Perjalanan Wisata Dengan Algoritma Tabu Search. Jurnal EECCIS Vol.7, No. 2 Desember 2013.

[5] Nugroho, Adi, ST, MM, Si. dkk. 2012. Rekayasa Perangkat Lunak Pendekatan Praktisi (Buku Satu). Penerbit: Andi. Yogyakarta.

[6] Suhartono, Dr. Vincent, dkk. 2011. Kecerdasan Buatan. Penerbit: Andi. Yogyakarta.

[7] Sari Paramita Helly, dan Daniel Udjulawa. 2014. Stimulasi Penentuan Rute Terpendek Menggunakan Tabu Search (Studi Kasus: Lokasi Wisata di Palembang). Teknik Informatika STMIK Global Informatika MDP. Palembang, ISSN: 2407-1102 Oktober 2014. Palembang.

[8] Togatorop, Disbun. 2014. Perancangan Aplikasi Pencarian Jalur Terpendek dengan Algoritma Tabu Search. Mahasiswa Jurusan Teknik Informatika STMIK Budi Darma, Medan, Pelita Informatika Budi Darma, Volume: VII, Nomor: 1 Juli 2014, ISSN: 2301-9425.

[9] Pressman RS. 2002. Rekayasa Perangkat Lunak Pendekatan Praktisi (Buku Satu). Yogyakarta: Andi.

[10] Whitten JL, Bentley LD, Dittman KC. 2004. System Analysis and Design Methods. Diterjemahkan oleh: Tim Penerjemah Andi. Yogyakarta: Andi. 